\title{
Astronomy-related organizations over the world
}

\author{
A. Heck \\ Observatoire Astronomique, 11 rue de l'Université, F-67000 Strasbourg, France \\ e-mail: heck@astro.u-strasbg.fr
}

Received March 31; accepted April 6, 1998

\begin{abstract}
The geographical distribution of astronomyrelated organizations is illustrated from comprehensive and up-to-date samples. Results for professional institutions, for public observatories, for planetariums, and for associations are commented and compared to an earlier study involving only observational locations (observing and receiving stations). Specific distributions of astronomy-related publishers and software producers are also illustrated.

There is a reinforcement of the tendencies pointed out in the previous study with very high densities in Europe and Northeastern U.S.A. Comments are offered on specific concentrations and national differences. It is also clear that numerous institutions and associations are not involved in direct observing. The astronomy-related publishers and software producers are interestingly concentrated in only a few places.
\end{abstract}

Key words: sociology of astronomy - astronomical datbases: miscellaneous

\section{Introduction}

This paper is the natural complement of an earlier study (Heck 1998b) devoted to the geographical distribution of observational activities for astronomy. The current contribution studies the geographical distributions of astronomy-related organizations over the world, professional as well as for amateur and grand public.

As in the previous paper, the data originate from the master files for StarGuides (Heck 1998a) and StarWorlds (Heck et al. 1994), the latter one being the WWW version of the former one which is a classical directory on paper (for a detailed presentation, refer to the previous study or to Heck 1997). The files are gathering together

Send offprint requests to: A. Heck all practical data available on associations, societies, scientific committees, agencies, companies, institutions, universities, etc., and more generally organizations, involved in astronomy and space sciences.

But many other related types of entries have also been included such as academies, advisory and expert committees, bibliographical services, data and documentation centres, dealers, distributors, funding agencies and organizations, journals, manufacturers, meteorological services, museums, norms and standards offices, planetariums, private consultants, public observatories, publishers, research institutions in related fields, software producers and distributors, and so on.

Besides astronomy and related space sciences, other fields such as aeronautics, aeronomy, astronautics, atmospheric sciences, chemistry, communications, computer sciences, data processing, education, electronics, energetics, engineering, environment, geodesy, geophysics, information handling, management, mathematics, meteorology, optics, physics, remote sensing, and so on, are also covered when justified. All the categories are appropriately flagged in a way that turned out to be very useful to sort out the entries as needed for the current study.

It is appropriate to remind here that we are dealing with validated and authenticated information (from signed and documented questionnaires), systematically compiled and presented, with a permament updatingprocess scheme. The expertise built up over now almost a quarter of a century in this exercise, as well as the overall stability of the master files, guarantee an excellent exhaustivity of the entries and an homogeneous coverage of the practical data gathered together. As it can be concluded from the illustrations, the distributions appear as not being biased by the various locations from which the compilations have been carried out (successively Belgium, Central Spain and Northeastern France) - in fact the places where we have been based during the last three decades.

The files used are certainly the best sources available today for the study at hand which was carried out 


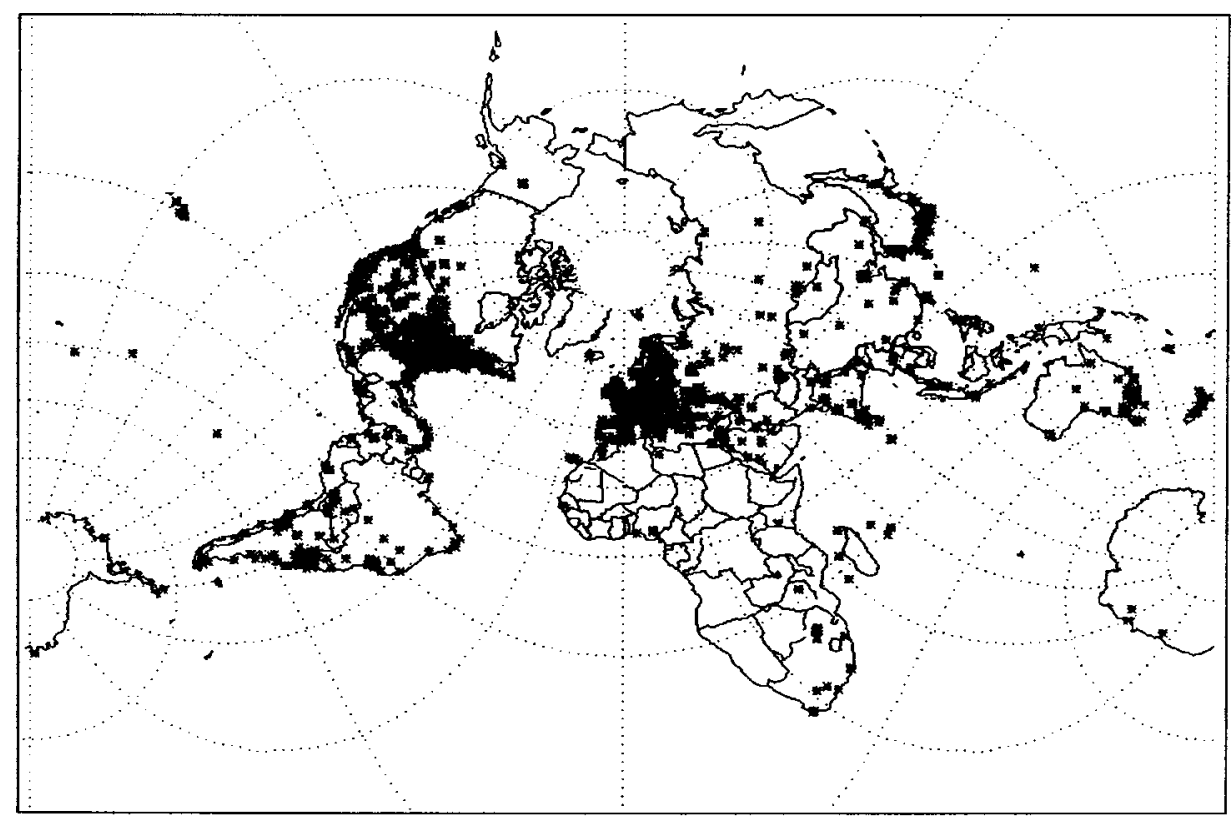

Fig. 1. StarGuides/StarWorlds' world (see text)

immediately after a major annual updating campaign. It should also be recalled here that, contrary to most on-line resources, StarWorlds is not only WWW-oriented.

Sets of coordinates are explicitly requested on our questionnaires and updating forms, but, as already explained in Heck (1998b), less than one third of the organizations register them. Therefore, to be able to carry out this study with all the entries in a systematic way, we entered for each of them a position based on the location of the organization head office or main centre of activities (hereafter called "city reference coordinates"). The coordinates were taken from a Rand McNally International Atlas (160 000 entries) and a Times Atlas of the World (210 000 entries) which appear to usefully complement each other and to be consistent as to their reference frame. A Rand McNally Zip Code Finder (for the US) as well as Michelin and Kümmerly+Frey road maps (essentially for European countries) were very helpful to locate from their postal codes small places not listed in the atlases. In such cases, the coordinates of the closest larger cities were recorded and explicitely mentioned as such in the master files. Complementary queries by mail and e-mail solved a few additional cases. Finally only 17 entries (0.28\%) have no coordinates.

\section{The maps}

We are presenting here the maps (drawn via IDL) that appeared to be the most interesting. Others can be produced of course and they can be requested from the author.

\subsection{General distributions}

At the time of writing, there were about 6050 entries in the master files, out of which about a thousand were simple cross-pointers. Thus the total number of effective organizations gathered together was about 5050 .

The total number of positions available from the files amounted to 6616 , including the positions registered by the organizations themselves (basically those used in Heck 1998b). For the record and as background references, Figs. 1 to 4 give the overall world distribution with blowups for Europe and North America, together with a stereographic view from the South Pole. These are all the geographical locations recorded in our files, what we call StarGuides/StarWorlds' world at the end of March 1998.

However there are only 4125 different physical locations. For the sake of legibility of the maps, the size the symbols (asterisks) has been kept the same, even if several points were superimposed. Some cities however present a significant concentration of entries such as (by decreasing order) Paris (79), Washington, DC (65), Tokyo (50), London, UK (49), Tucson, AZ (37), New York (34), Boulder, CO (31), Moscow (29), Cambridge, MA (27), Brussels (25), Pasadena, CA (25), Roma (22), Houston, TX (21), just to take those over twenty occurrences.

Thus Paris ranks first and a blowup centered on France (not reproduced here) shows also a very strong concentration around Paris itself (the "Île-de-France" region) - another illustration, if needed, of the French centralization. Locations are more spread out in countries such as the UK and Germany for instance.

The largest concentrations of astronomy-related organizations are located in Europe and the USA (Northeast 


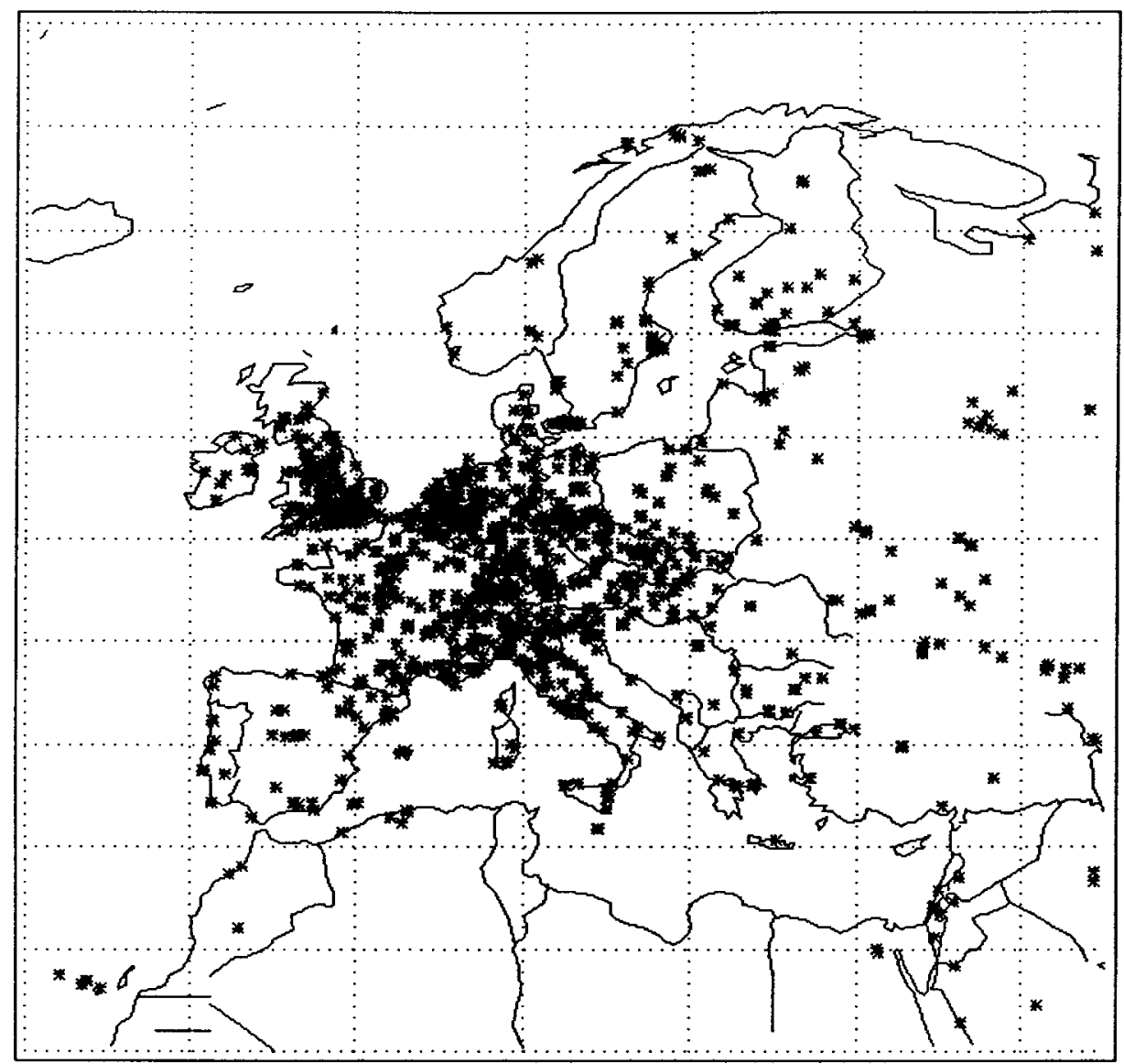

Fig. 2. StarGuides/StarWorlds' world — European blowup (see text)

and California), with a few nuclei in Japan, Australia, New Zealand, India, as well as a few spots in South America. This is consistent with and reinforces what was already appearing from the observational activities only, although with some nuances as it will be seen later on.

Before going on to more specific distributions, it seemed interesting to have a look at the distribution of organizations who have already a site or at least pages on the World-Wide Web (WWW), about five years after this medium started spreading quickly over the world. Our master files have also reached an acceptable maturity and exhaustivity in this respect with about 5000 URLs since quite some time already (a figure which is only very slowly increasing now compare with what was happening a couple of years ago). This corresponds to 3417 organizations.

Figures 5 to 7 give the world distribution of entries offering WWW pages, with enlargements for Europe and North America. It is striking how France, Spain and Portugal have significantly much lower densities than their European neighbours, obviously lagging behind as to the penetration of the WWW.

\subsection{Specific distributions}

As in Heck (1998b), it seemed appropriate to sort out the entries in several basic categories: institutions, public observatories, planetariums, and finally associations. The first one is clearly related to professional astronomers. The latter ones deal mainly with amateur astronomers and the grand public. They have strongly similar educational missions. They could of course be merged for a statistical investigation such as the current one, but it should be kept in mind that public observatories and planetariums have a more official structure and a better stability (mainly because of the buildings, equipment, and personnel involved) than most associations, the nature of which is consequently different.

\subsubsection{Professional institutions}

Out of a total of about 1800 institutions registered at the time of writing, we retained 1155 city reference positions corresponding to those who clearly indicated a definite research activity in astronomy. As in the previous study, some borderlines had to be adopted and we did it by making the best usage of the registered profile of activities and of the information provided by the organizations 


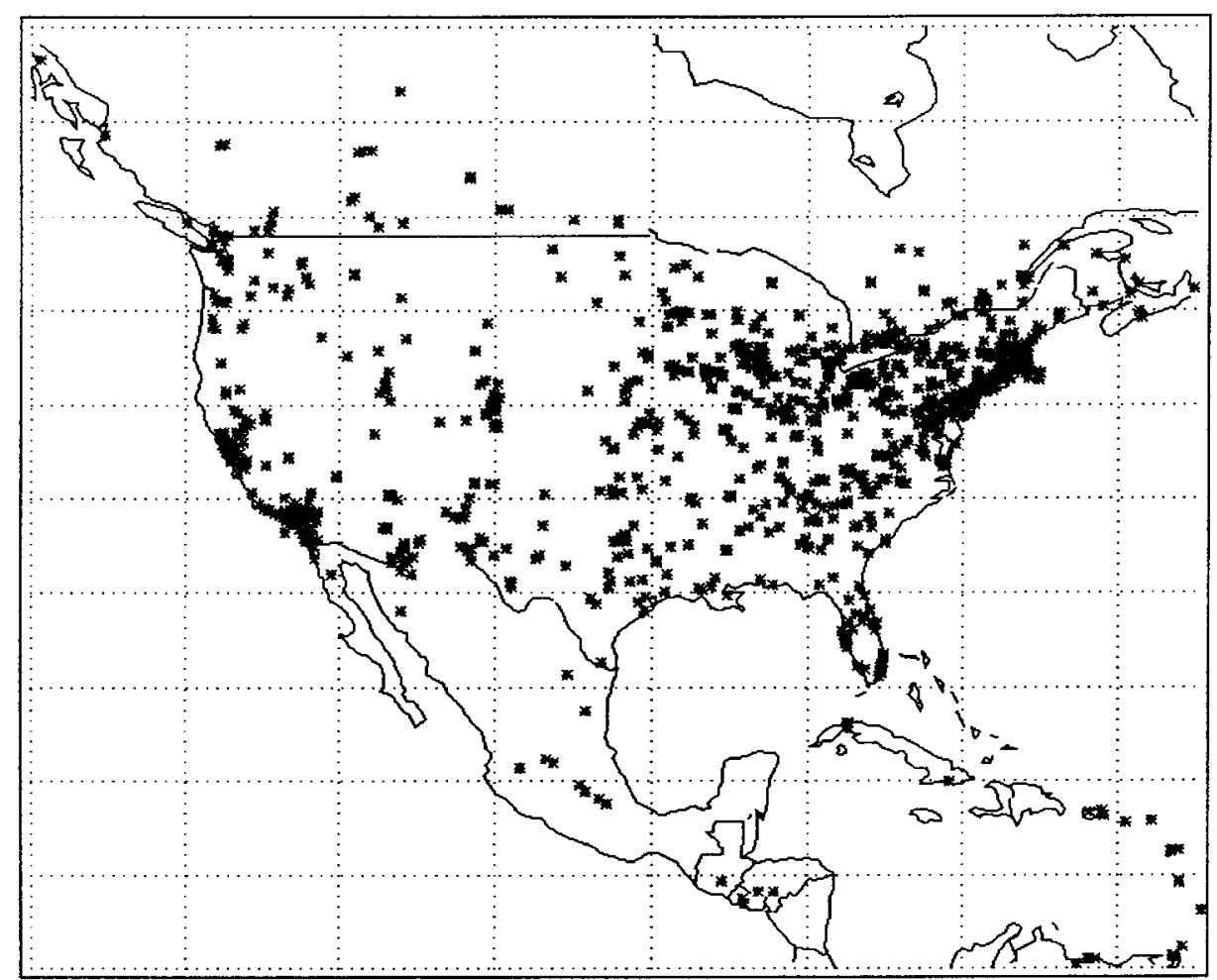

Fig. 3. StarGuides/StarWorlds' world — North American blowup (see text)

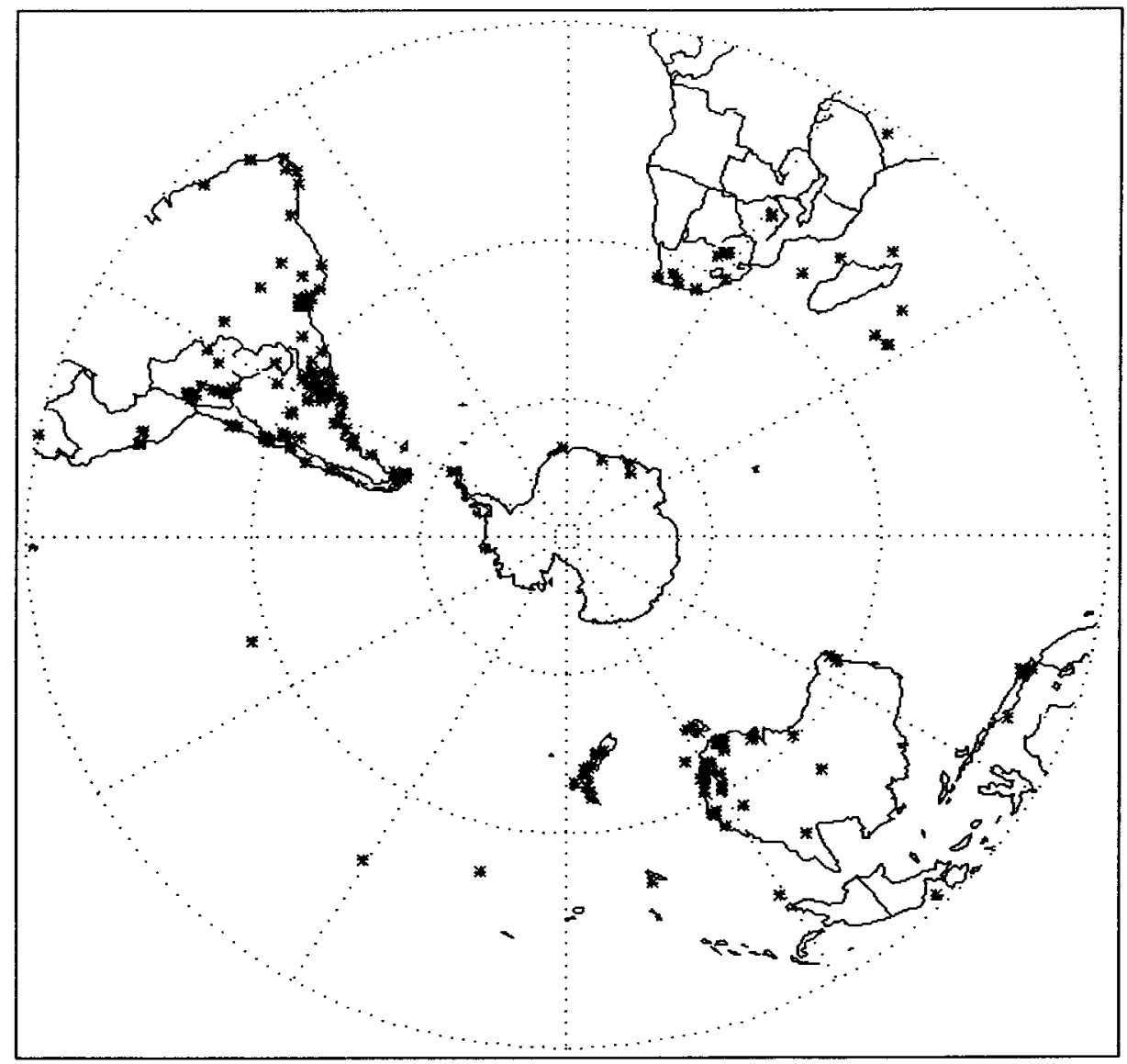

Fig. 4. StarGuides/StarWorlds' world — Stereographic view from the South Pole (see text) 


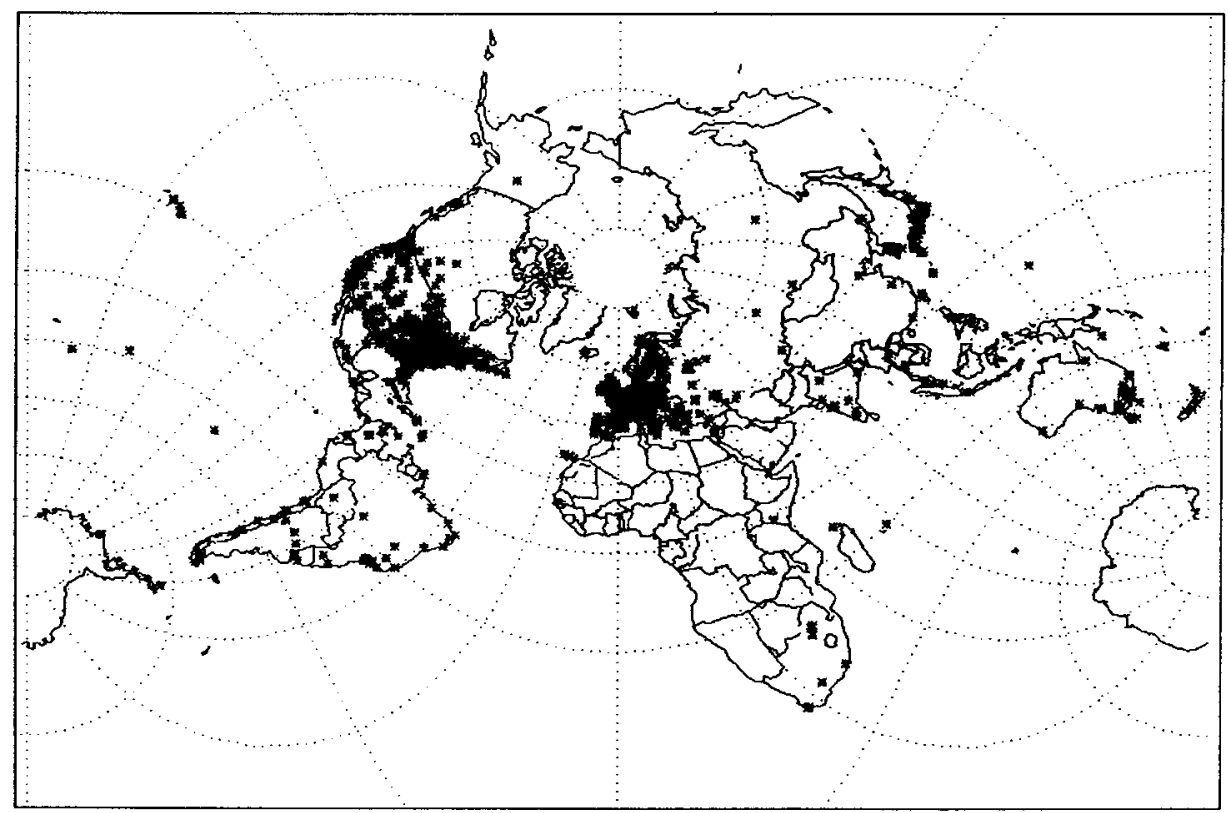

Fig. 5. World distribution of organizations with WWW pages (see text)

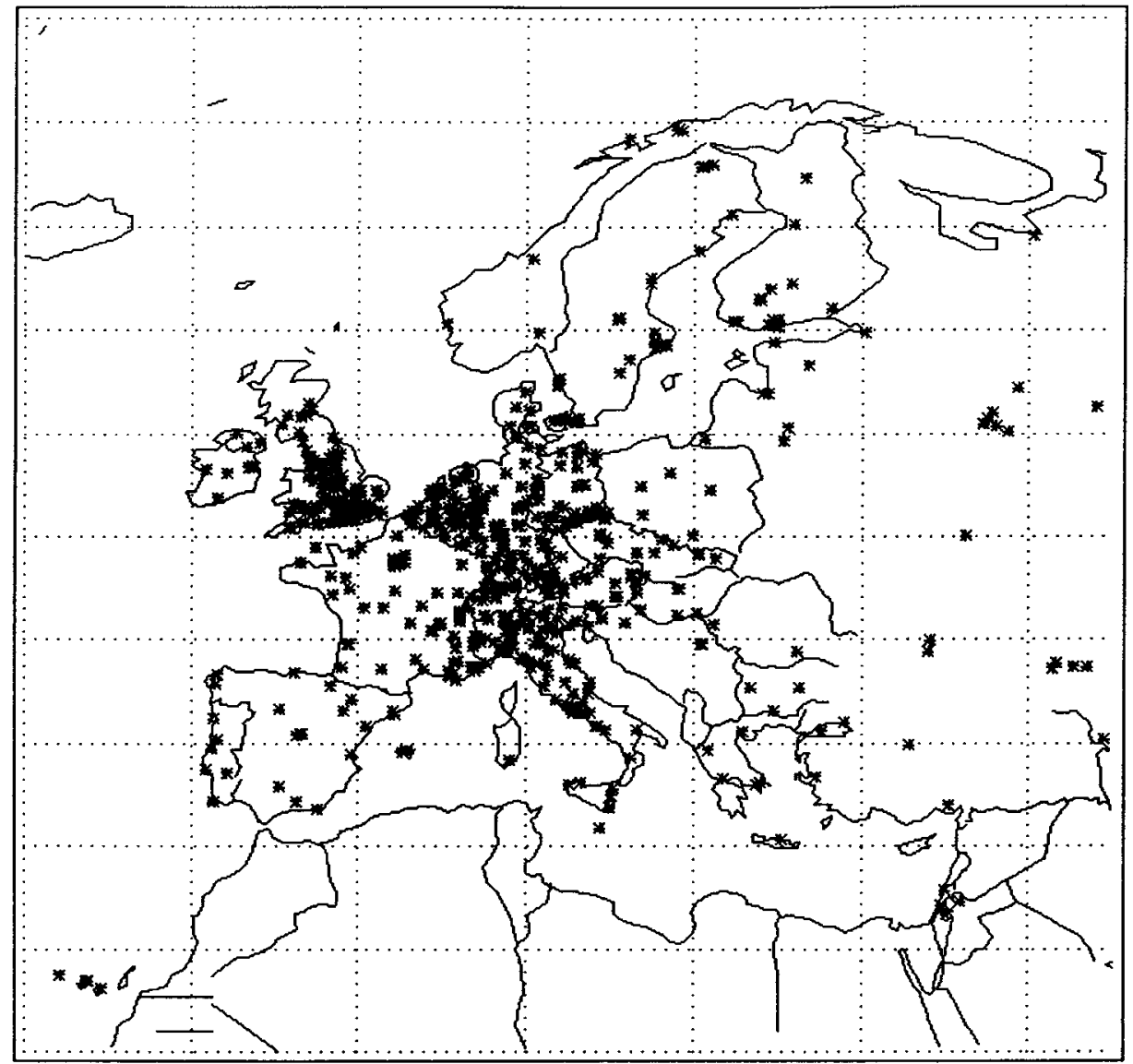

Fig. 6. European distribution of organizations with WWW pages (see text) 


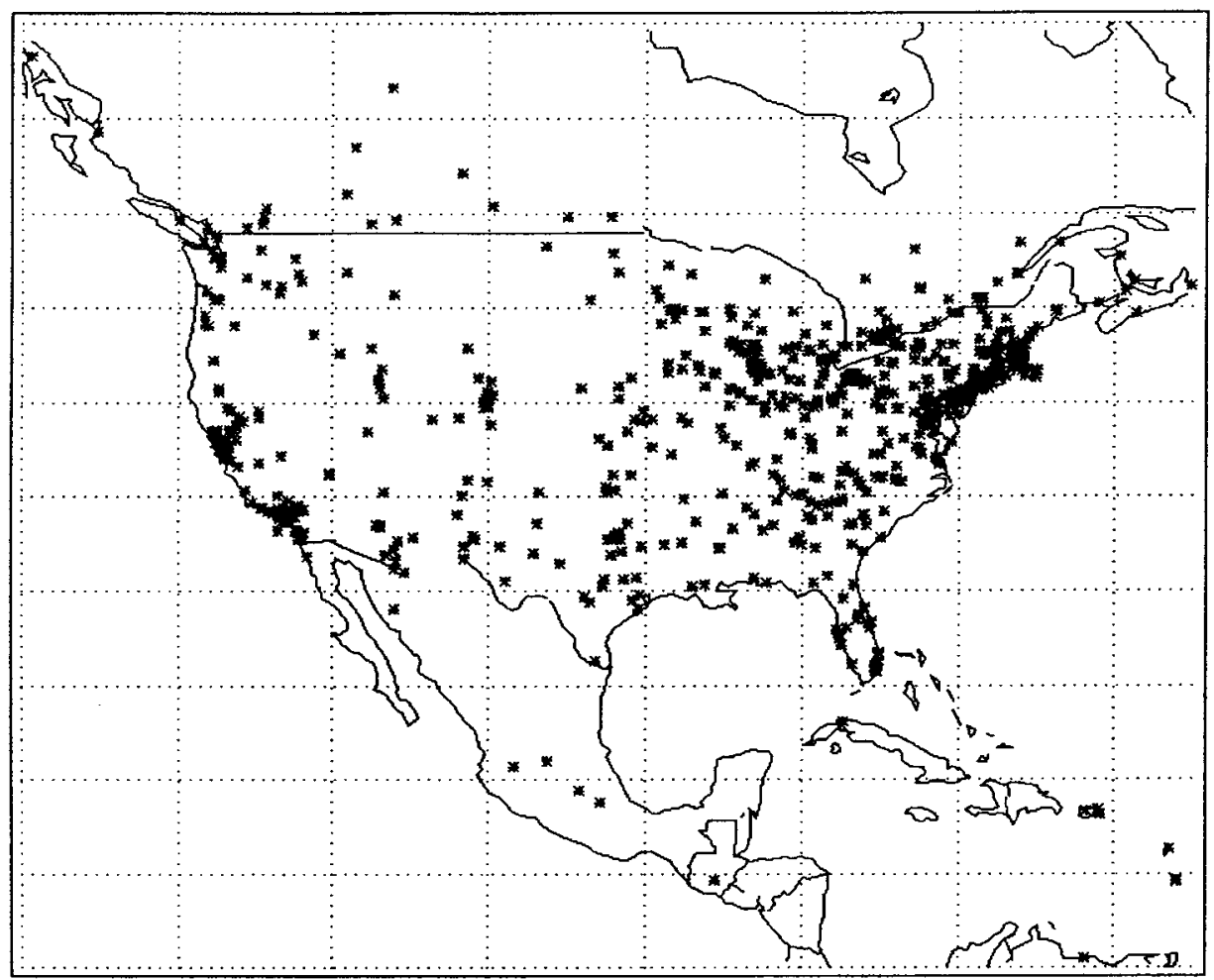

Fig. 7. North American distribution of organizations with WWW pages (see text)

themselves (as part of the authentication/verification process, we request a report of activities). Figures 8 to 11 give the world distribution of all astronomy-related institutions with enlargements for Europe and North America, together with a stereographic view from the South Pole.

\subsubsection{Public observatories}

There were 329 city reference positions in the master files registered for public observatories. These are institutions set up specifically to deal with the public at large (and thus they do not include professional institutions that might be occasionally or routinely open for public visits). Figures 12 to 14 show the world distribution of public observatories with enlargements for Europe and North America.

\subsubsection{Planetariums}

There were 464 city reference positions registered for planetariums in the master files. Note that there is definitely some overlap with the previous category as planetarium buildings are often hosting observing facilities and as some public observatories host also a planetarium. We also included here planetariums of educational institutions (universities, high schools, etc.) when used for public shows.
Figures 15 to 17 show the world distribution of public observatories and planetariums with enlargements for Europe and North America.

\subsubsection{Associations}

We could use up to 1150 city reference locations for the astronomical associations registered in the master files, which is more than four times as much as in Heck (1998b) where again only the locations of observational activities were considered. Figures 18 to 20 show the world distribution of associations with enlargements for Europe and North America.

\subsubsection{Other distributions}

There is of course the possibility to draw geographical distributions for all the categories of entries mentioned in Sect. 1, but we retained only two that seemed appropriate in this study: astronomy-related publishers and software producers. Figures 21 to 23 show the world distribution of astronomy-related publishers (202 positions) with enlargements for Europe and North America. Figures 24 to 26 give the same for astronomy-related software producers (181 positions). These distribute generally commercial products. Specific software packages developed in scientific institutions were not considered here. 


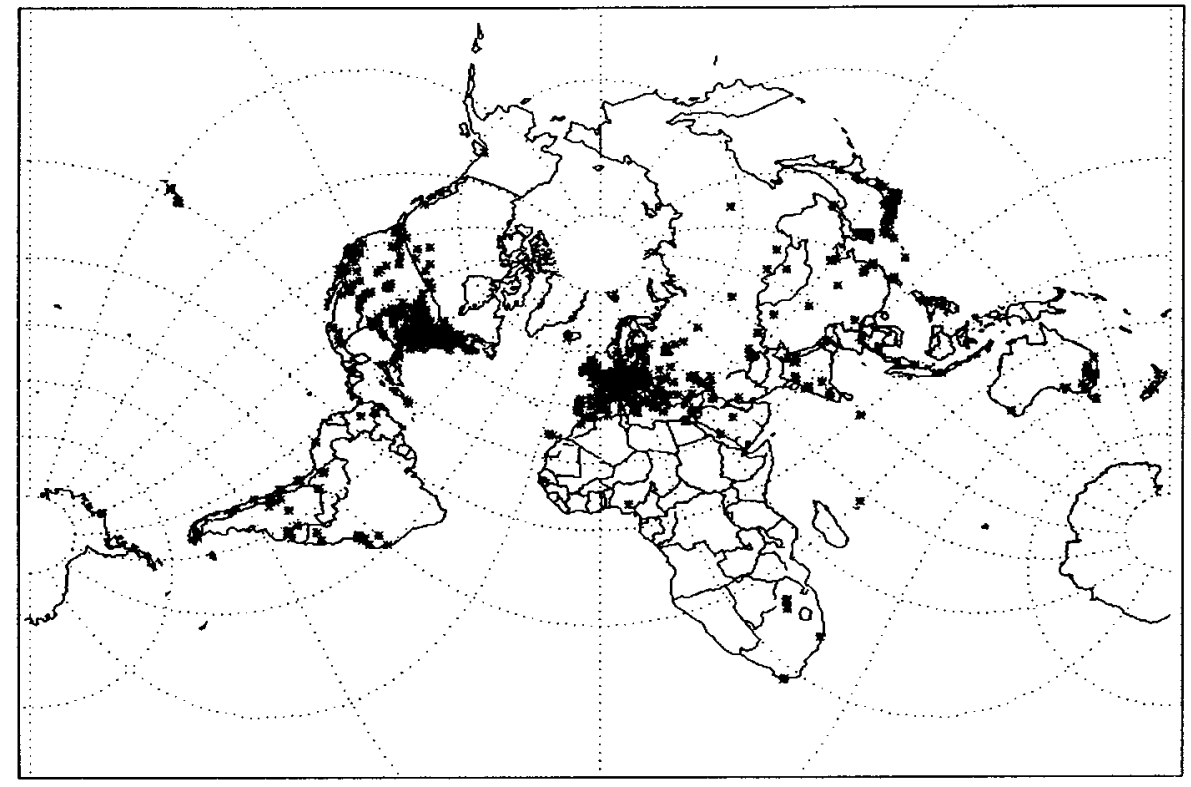

Fig. 8. World distribution of institutions (see text)

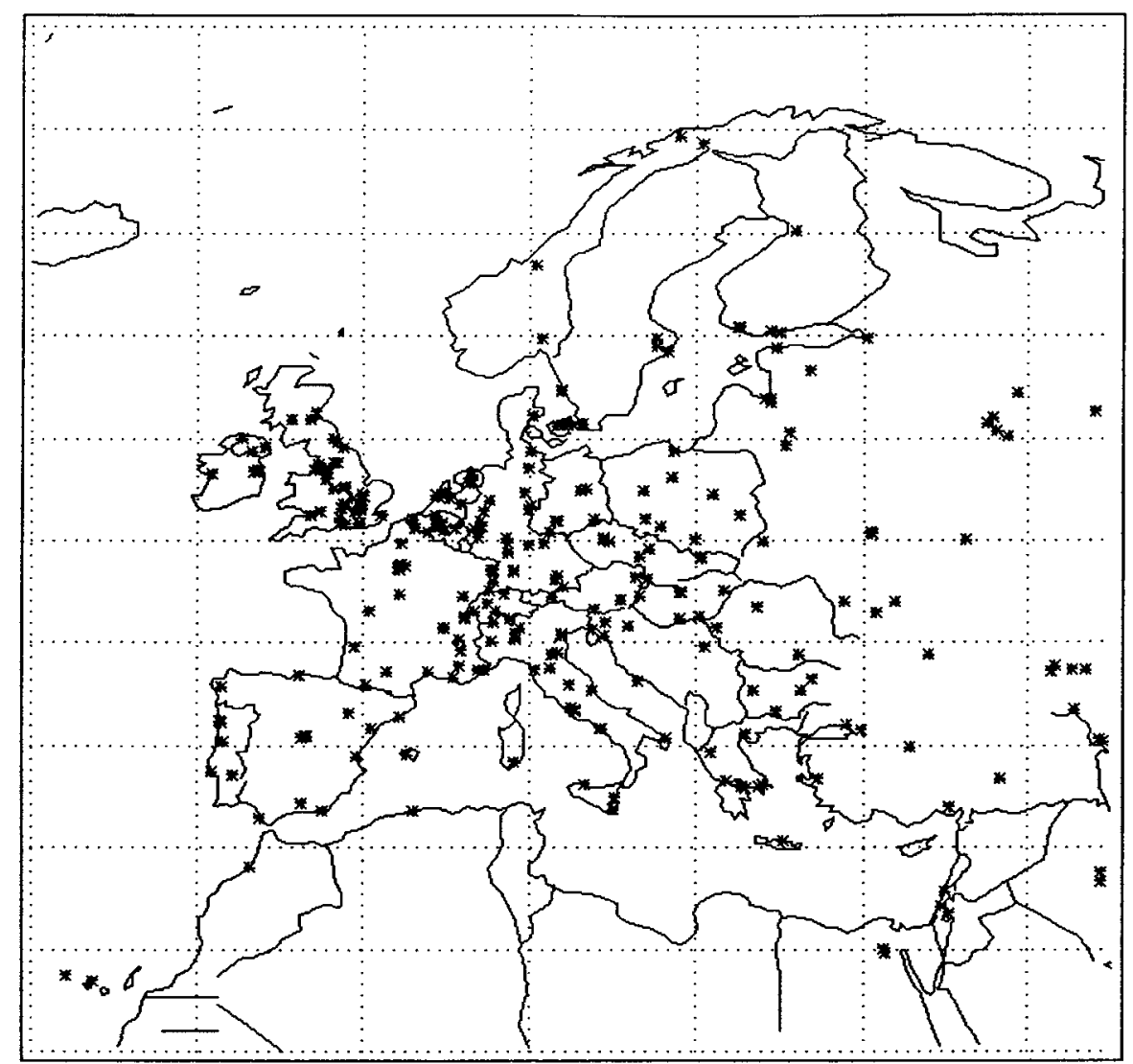

Fig. 9. European distribution of institutions (see text) 


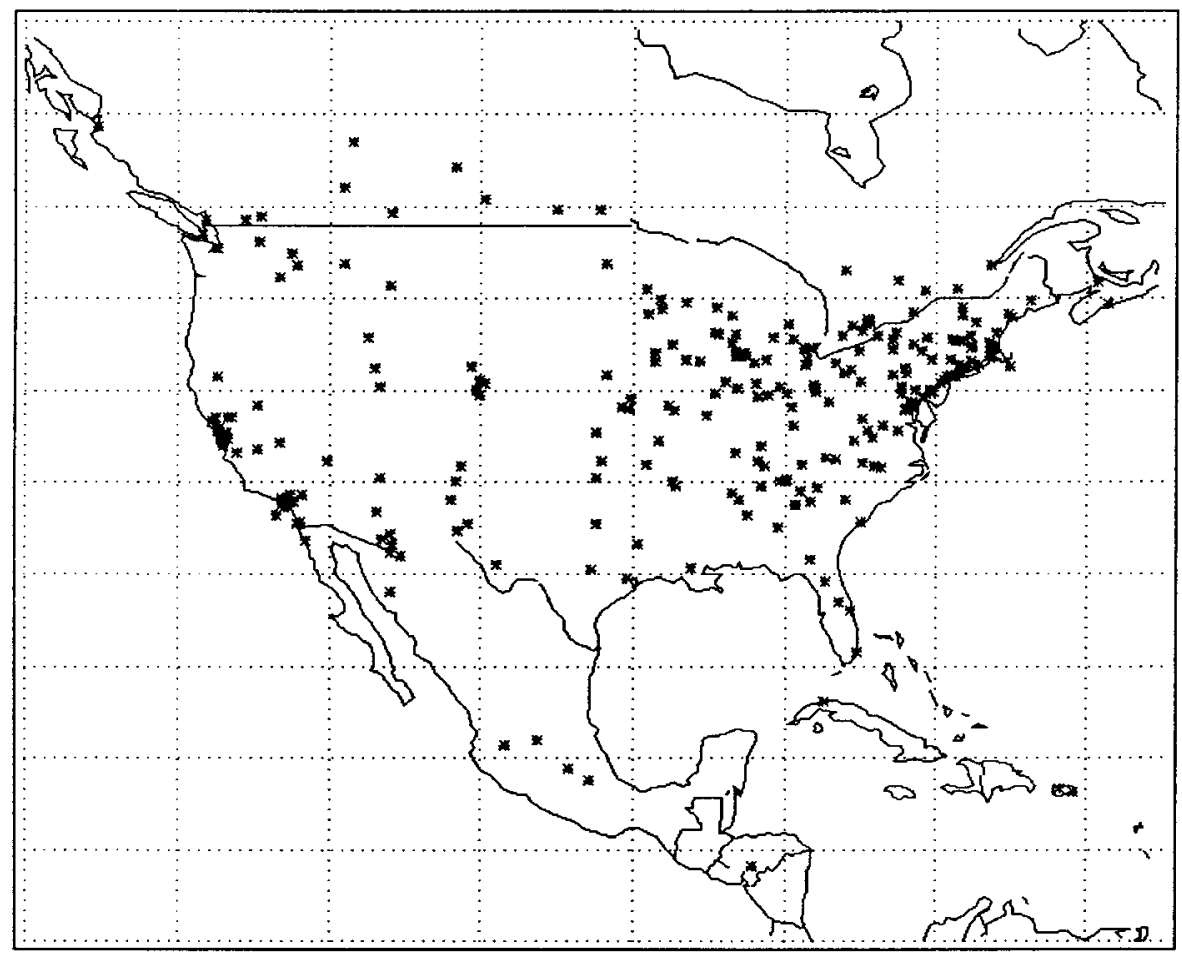

Fig. 10. North American distribution of institutions (see text)

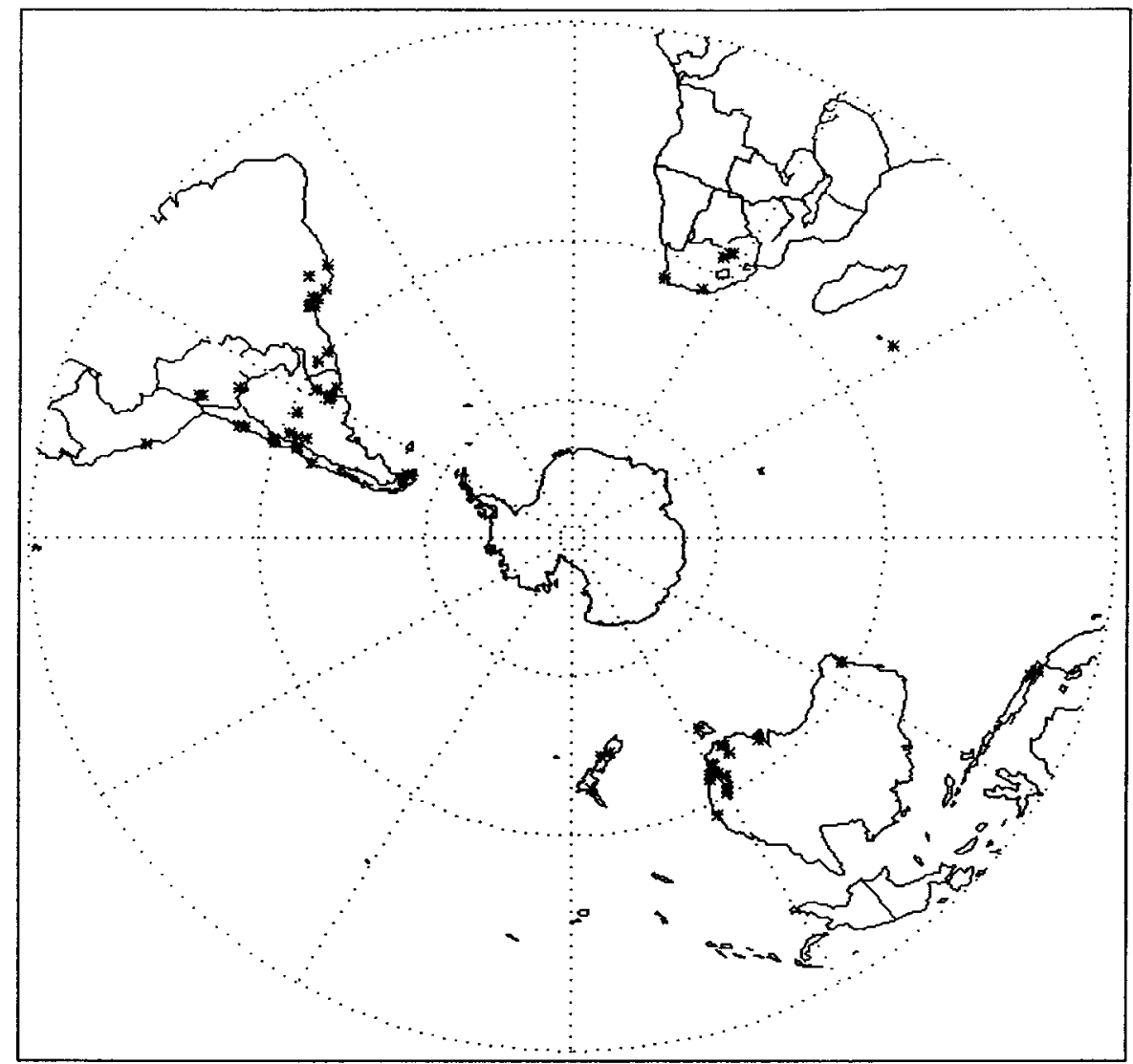

Fig. 11. Southernmost distribution of institutions (see text) 


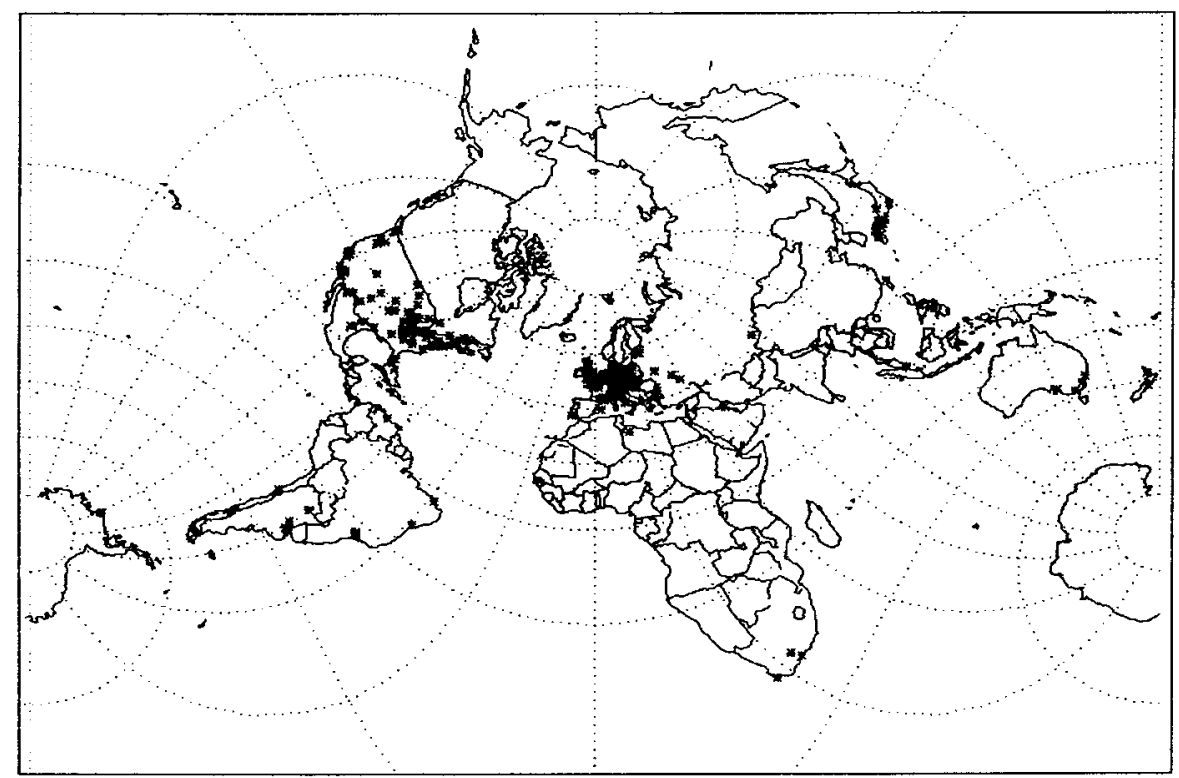

Fig. 12. World distribution of public observatories (see text)

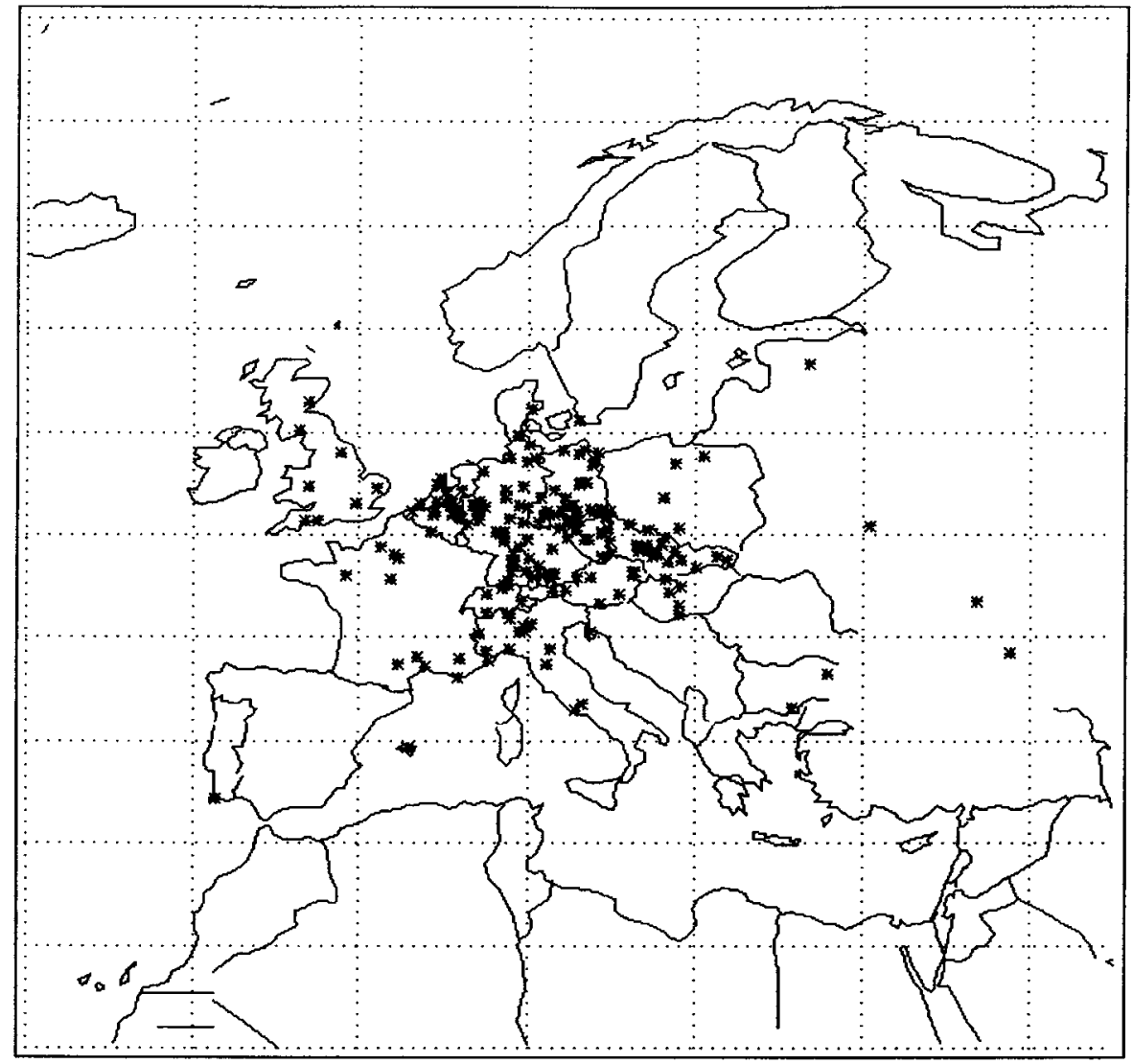

Fig. 13. European distribution of public observatories (see text) 


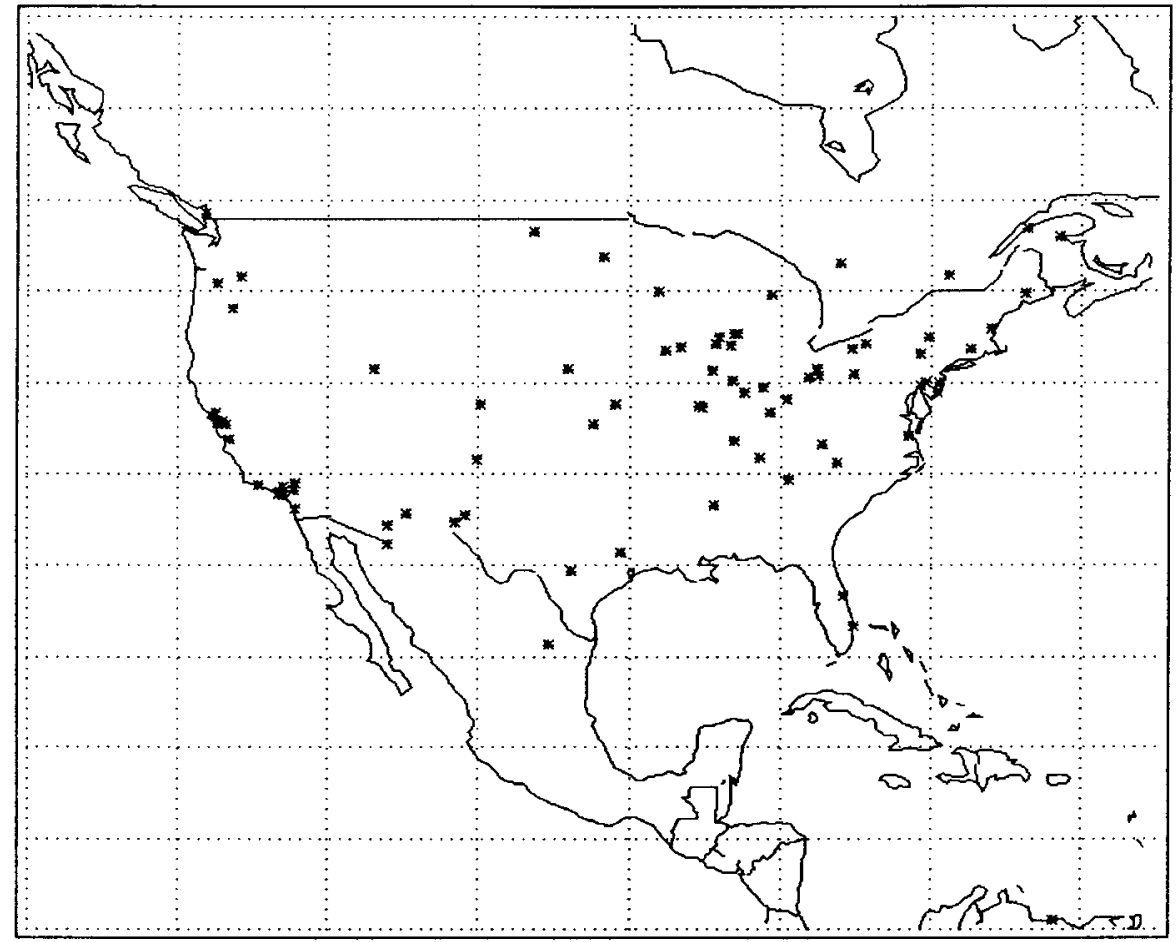

Fig. 14. North American distribution of public observatories (see text)

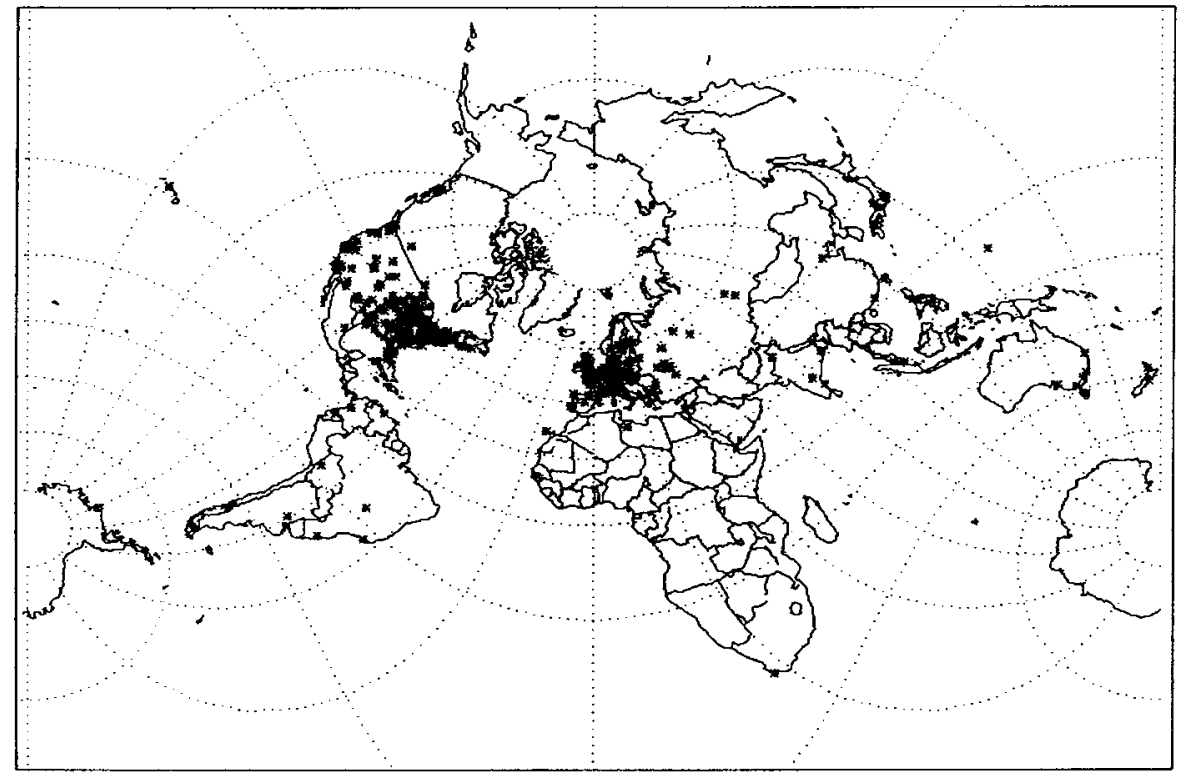

Fig. 15. World distribution of planetariums (see text) 


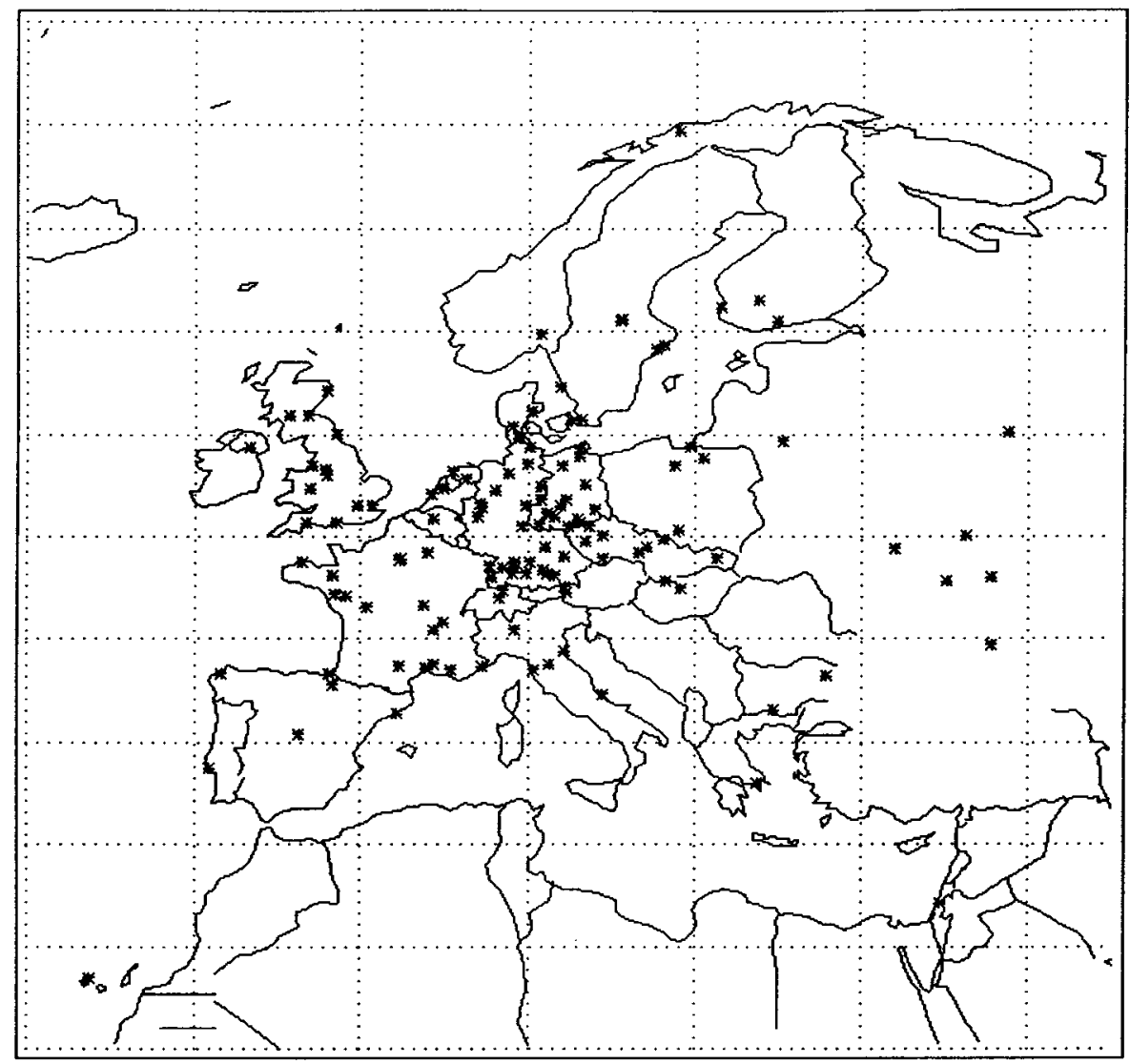

Fig. 16. European distribution of planetariums (see text)

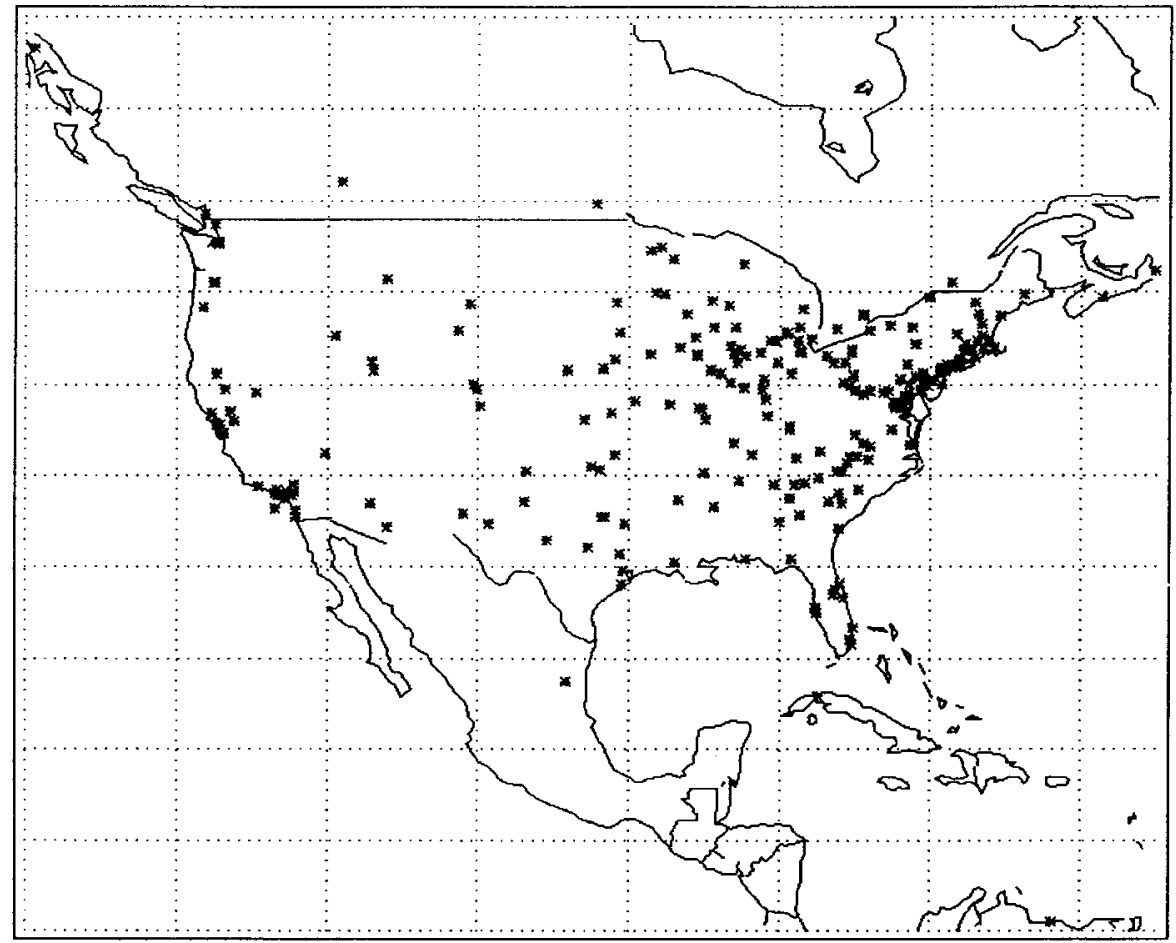

Fig. 17. North American distribution of planetariums (see text) 


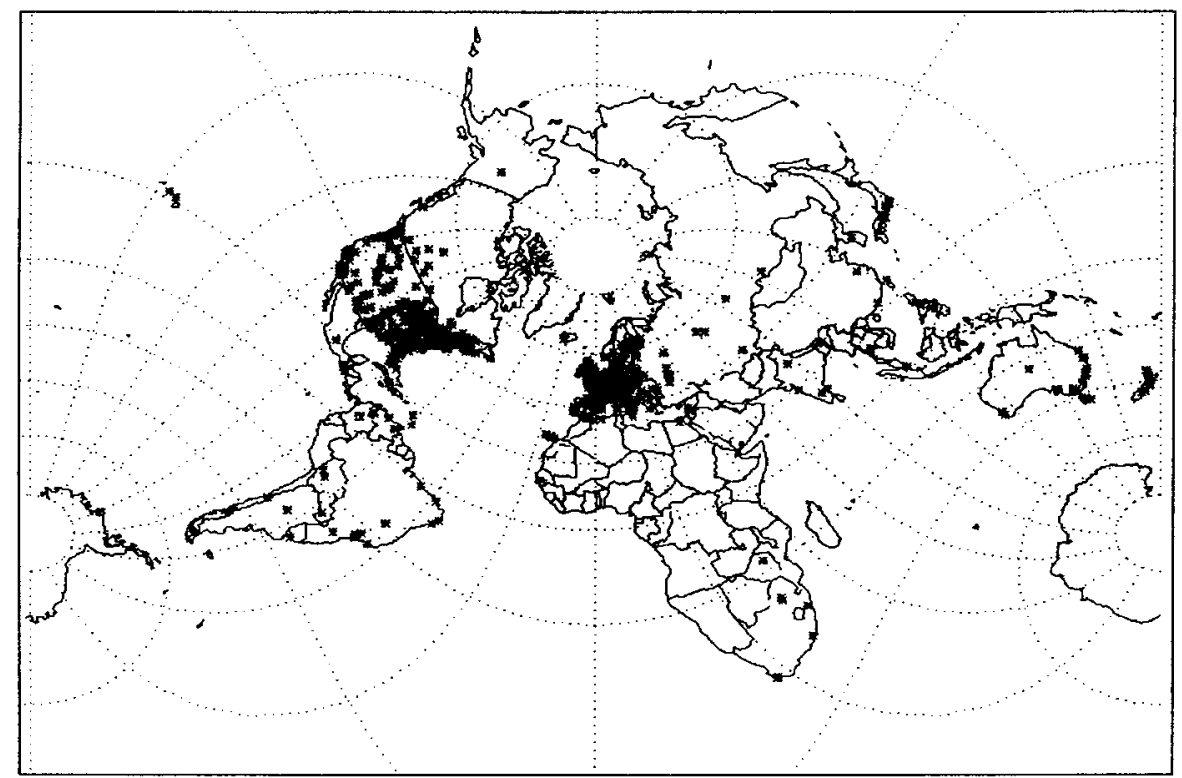

Fig. 18. World distribution of associations (see text)

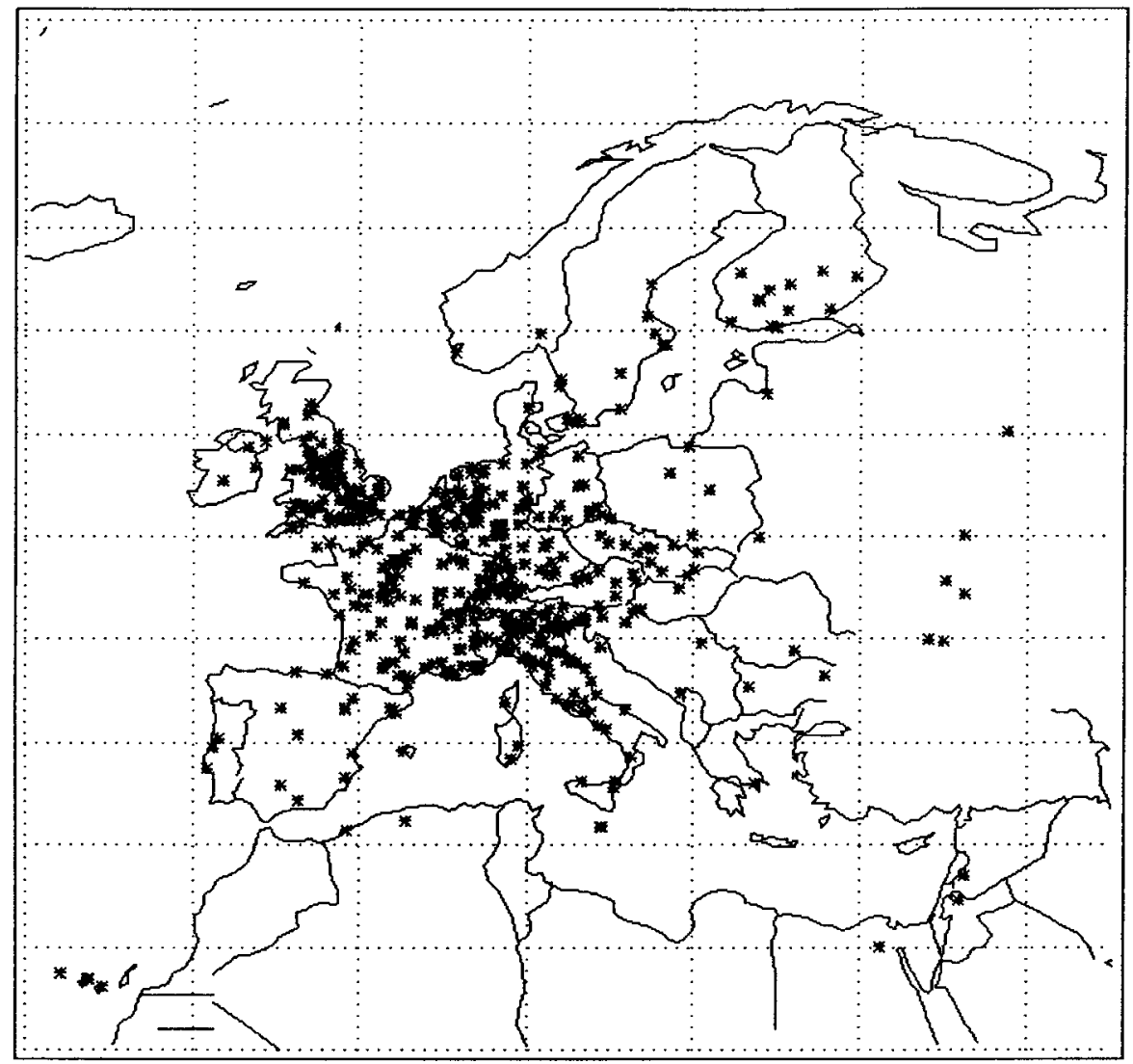

Fig. 19. European distribution of associations (see text) 


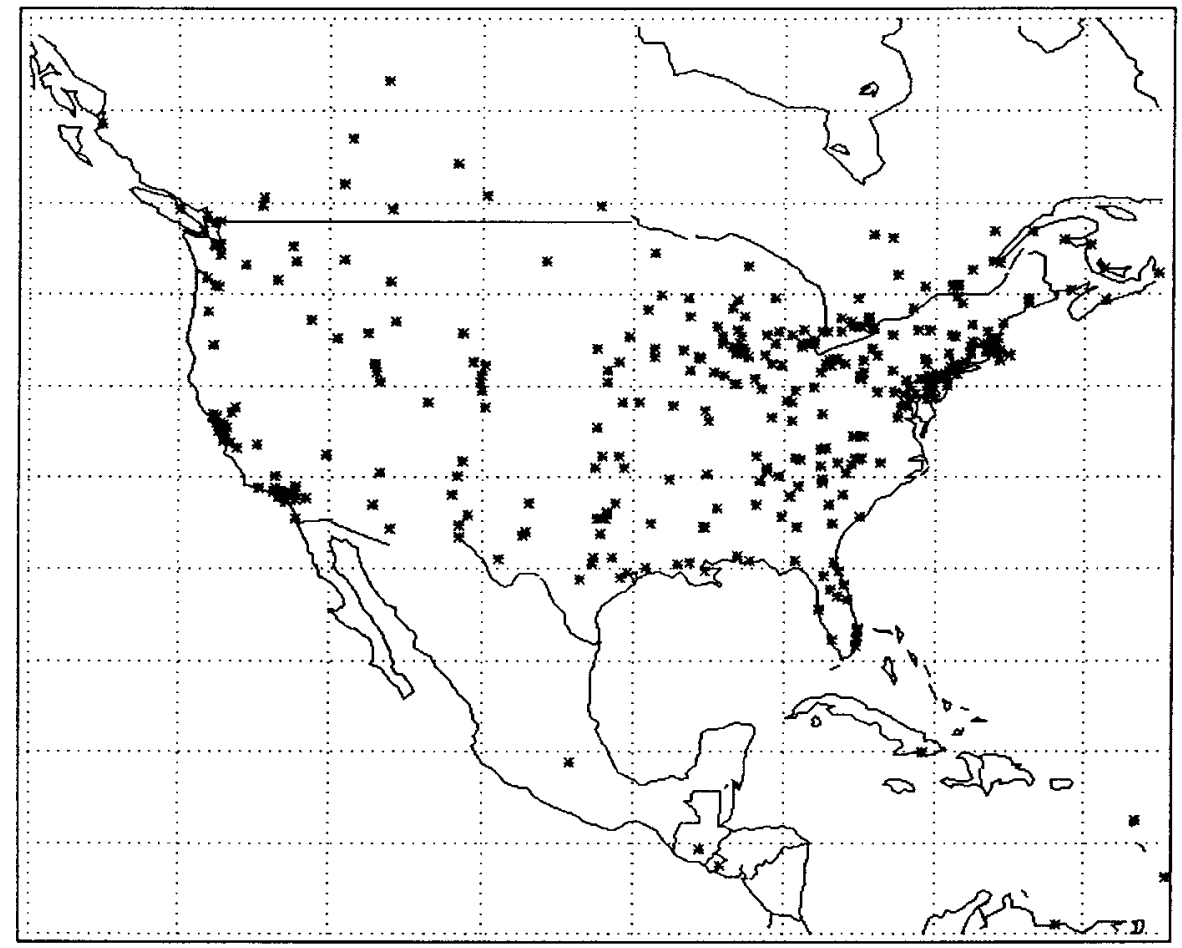

Fig. 20. North American distribution of associations (see text)

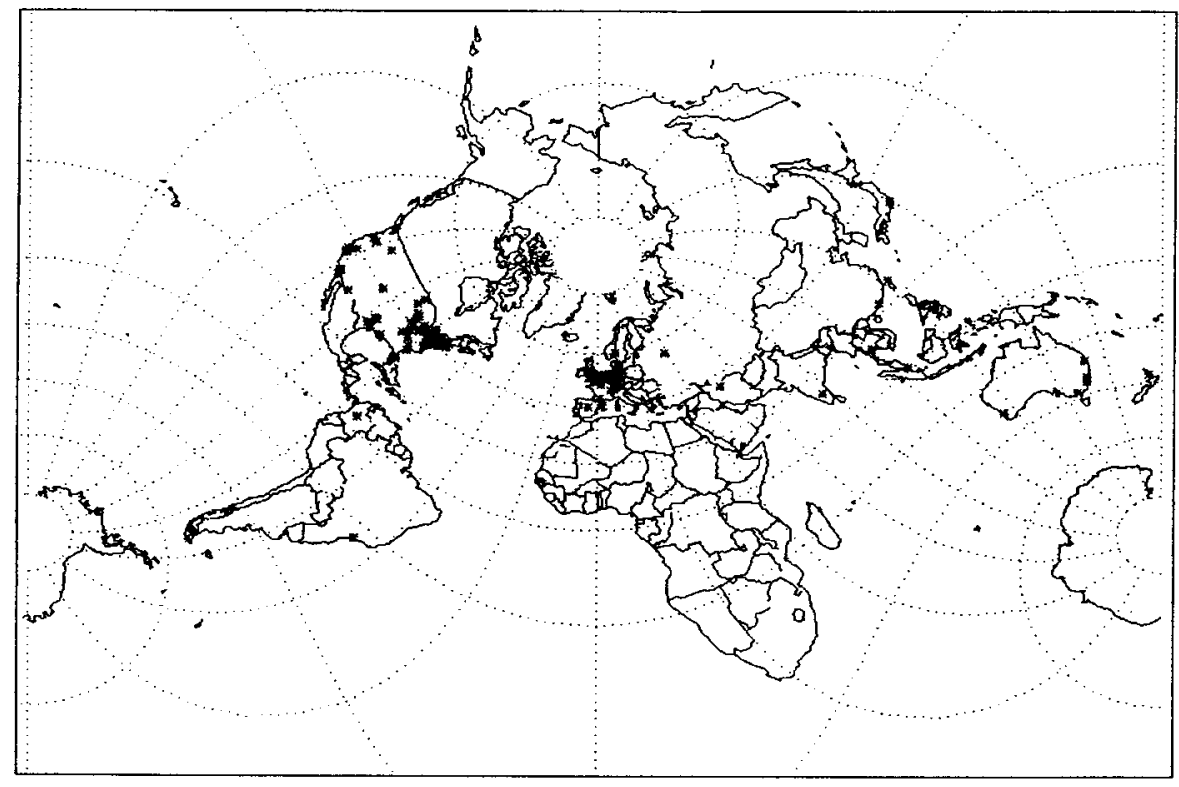

Fig. 21. World distribution of astronomy-related publishers (see text) 


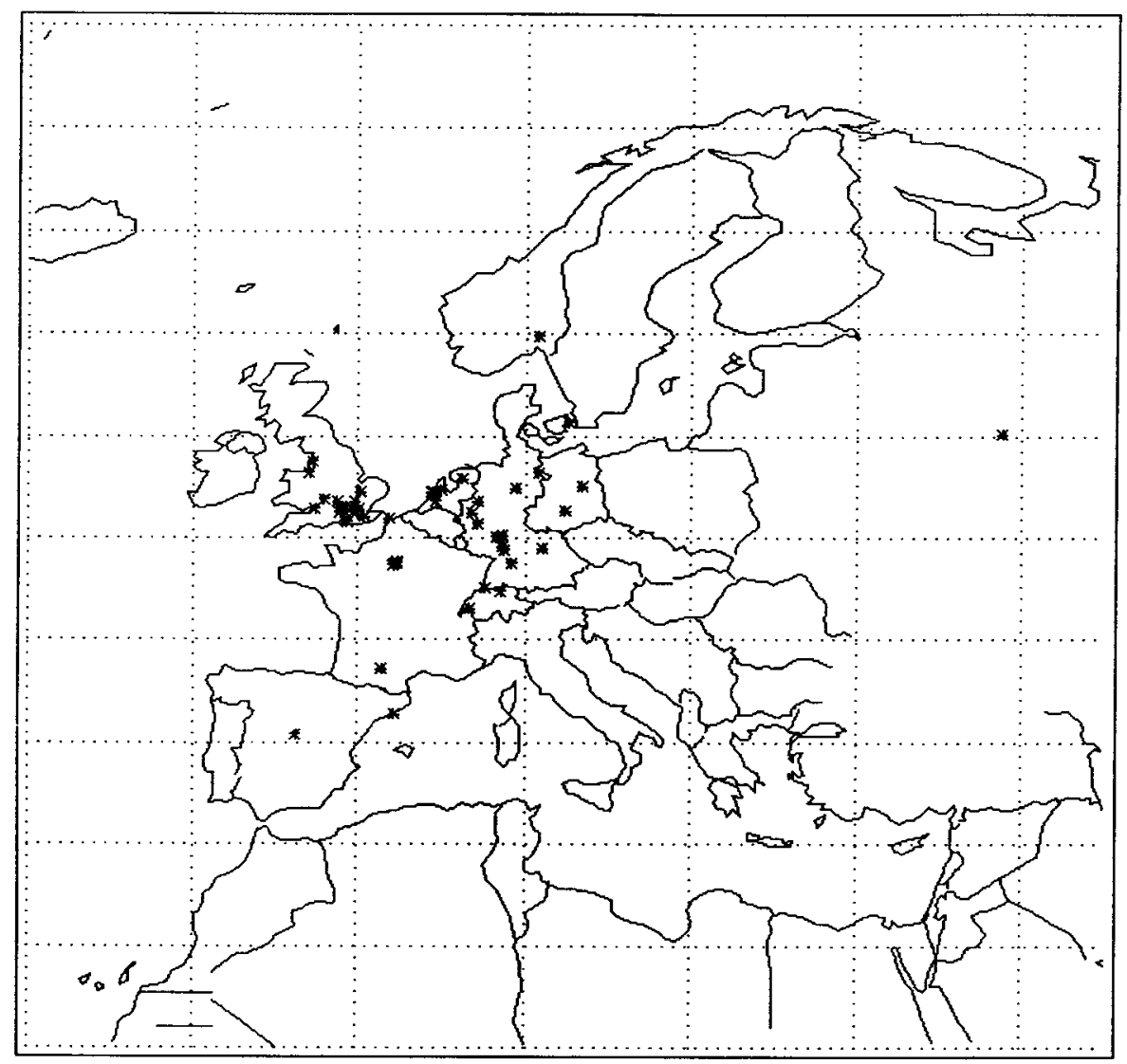

Fig. 22. European distribution of astronomy-related publishers (see text)

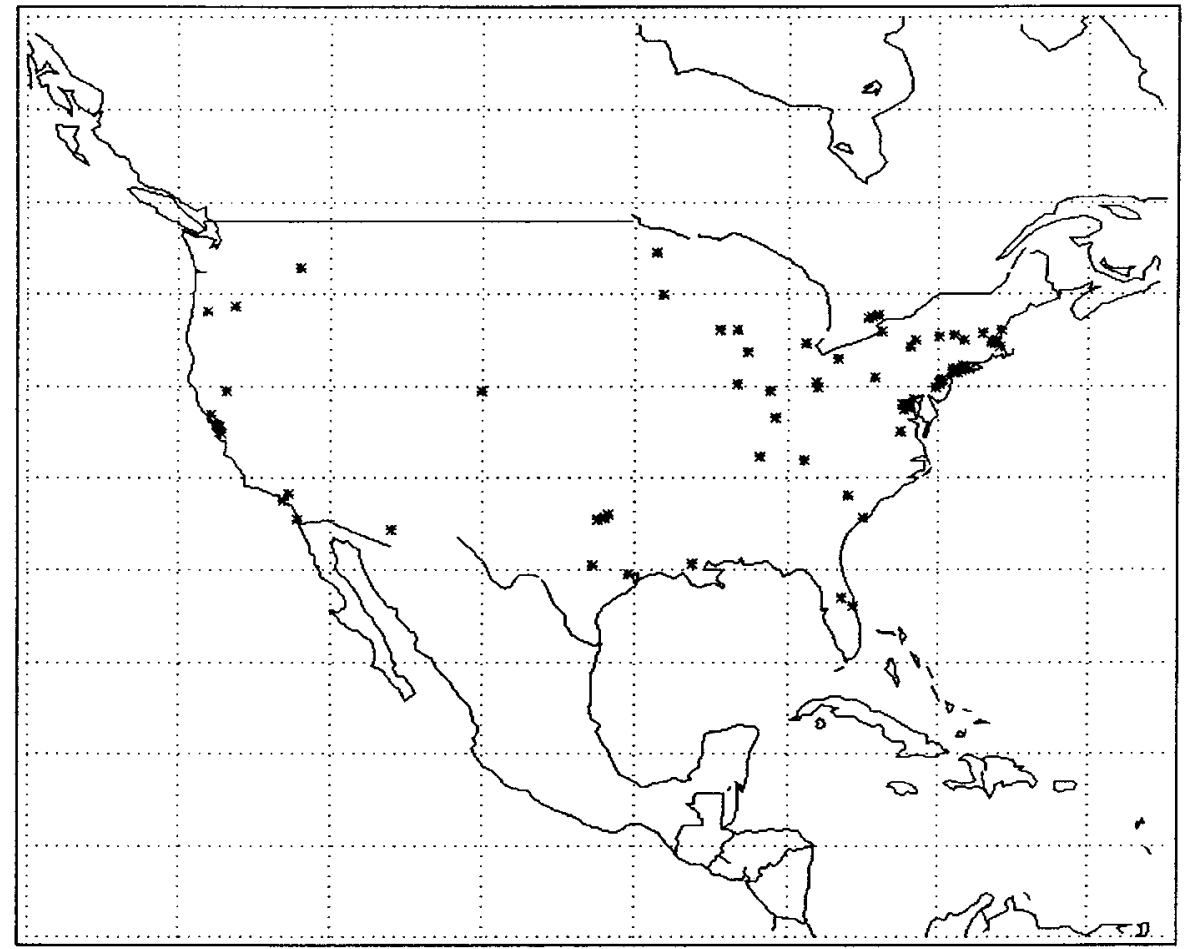

Fig. 23. North American distribution of astronomy-related publishers (see text) 


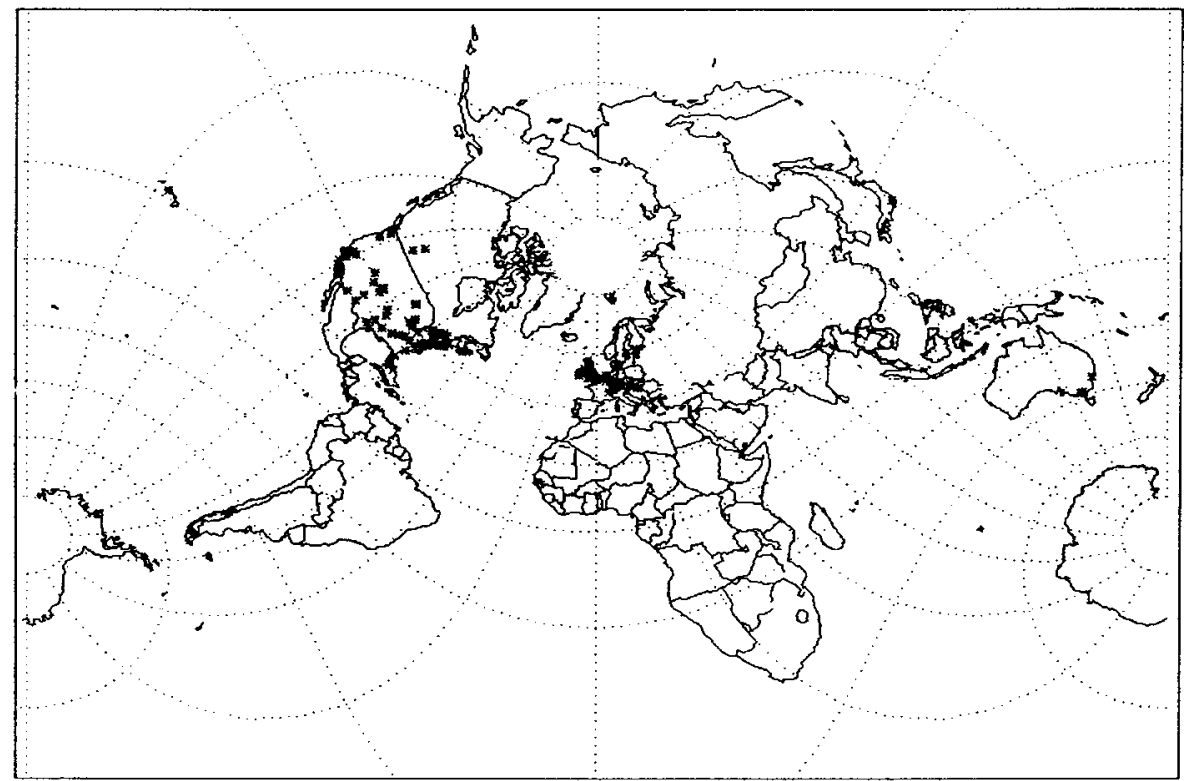

Fig. 24. World distribution of astronomy-related commercial software producers (see text)

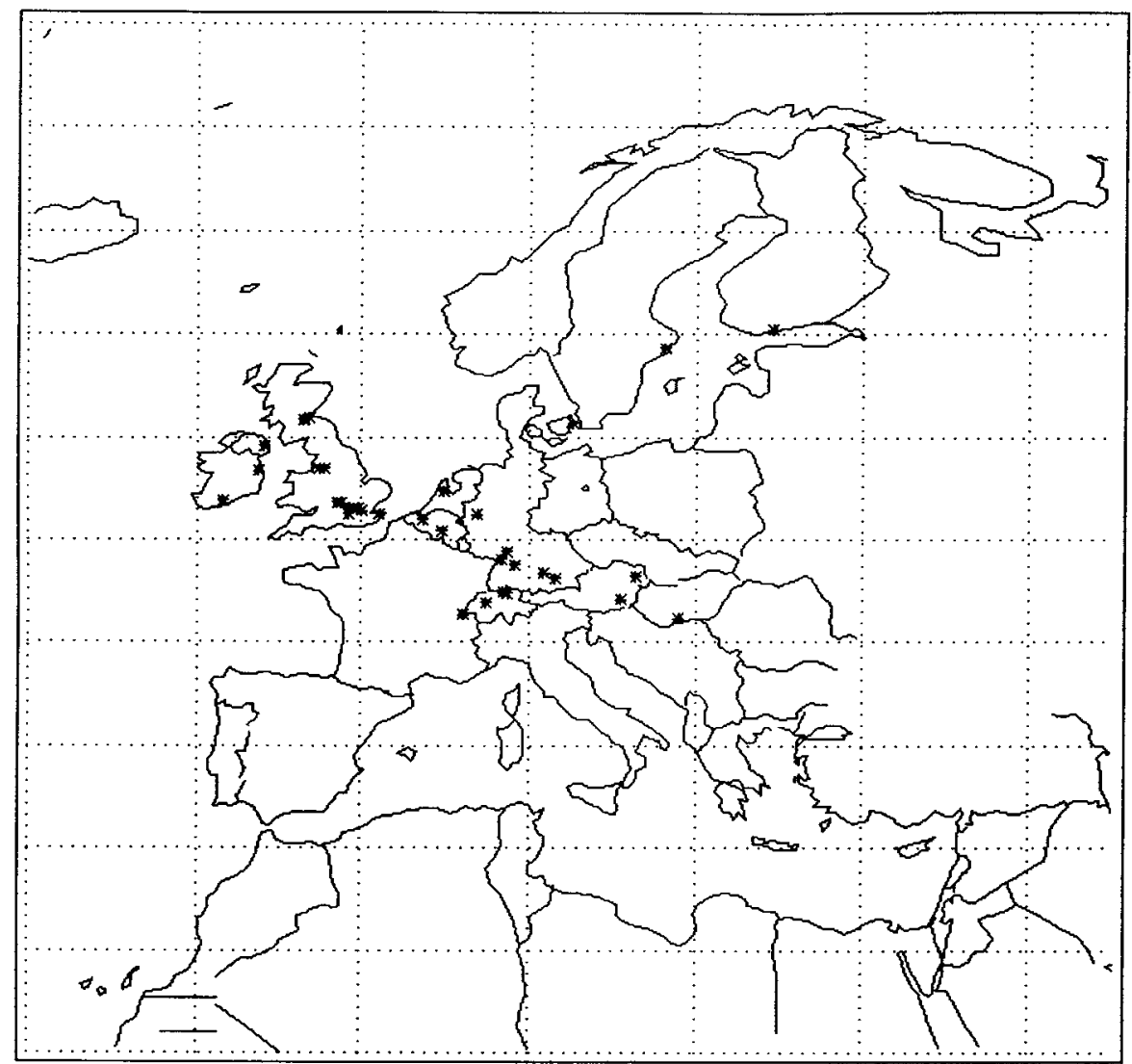

Fig. 25. European distribution of astronomy-related commercial software producers (see text) 


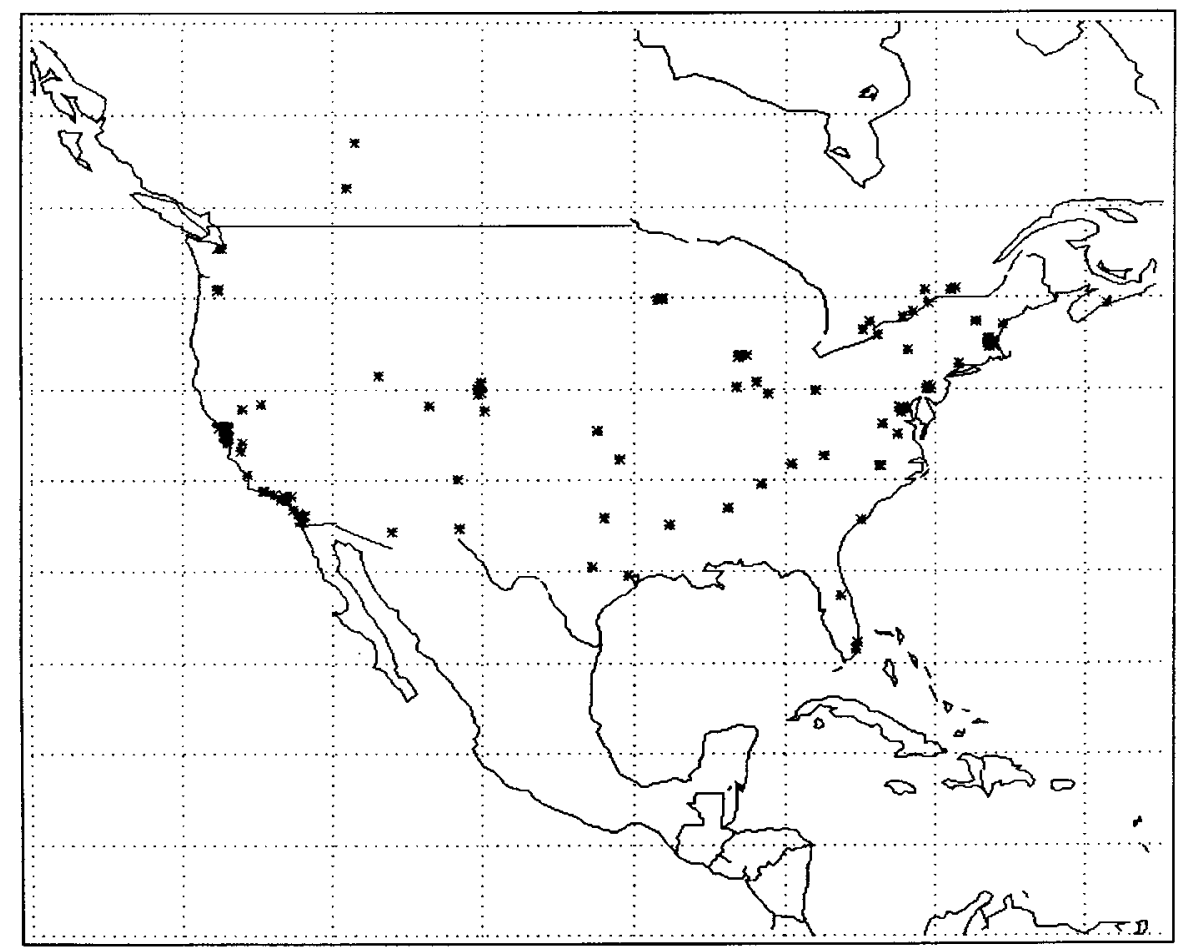

Fig. 26. North American distribution of astronomy-related commercial software producers (see text)

\section{Comments}

When dealing with this kind of statistical distributions, it is important to refrain from pushing the analysis of the data too far and to stay at an appropriate level: a global analysis, rather than a location-per-location perusal.

Apart from strong densities in Europe and the Eastern half of the U.S.A., the most striking feature - common to all categories - is the desperate emptiness of most of the African continent. A similar comment is also of application to quite a number of the so-called third-world countries. This was already an important conclusion of the previous study and it is reinforced here since the maps have been obtained with much larger samples.

The general aspects of the corresponding distributions between the various categories considered in this study are similar, with some nuances though.

As far as professional institutions are concerned, we see also a reinforcement of the nuclei of the previous study, albeit more spread out and with the disappearance of typical observing stations (in Antarctica, for instance). The concentrations of institutions in areas such as Paris, Moscow, and so on, are clearly noticeable.

The samples of public observatories and planetariums have to be compared to the combined corresponding sample in the previous study, but the total size here would be about three times as large as in Heck (1998b) where only the locations of observational activities were used. There is also a reinforcement of the tendency noticed in Heck (1998b): a much higher density of points in the Netherlands, Germany and central European countries. This confirms what we identified as a cultural component or a result of deliberate national policies.

As to associations, the maps show a dramatic reinforcement of locations in countries such as Germany, Switzerland, Italy, and so on. This implies that the average associative activity profile is significantly away from observing. Not too surprizingly, the US nuclei are located in the Northeast and California, together with a definite one in Washington State.

Concentrations of astronomy-related publishers are to be found in and around London, Paris, Amsterdam, with some others in Germany and of course in Northeastern USA and California.

If the sample of astronomical-software producers is the smallest one (thus requiring more caution in statistical interpretation) and if the US pattern is what can be reasonably expected, the European distribution is extremely surprising: mainly along a line from Dublin to Budapest.

Acknowledgements. We are very grateful to all persons and organizations wo contributed over the past quarter of the century to the very substance of the master files used here by returning the questionnaires, by providing the relevant documentation, by participating in the various procedures of maintenance, validation and verification of the information, or otherwise. 


\section{References}

Heck A., 1997, Electronic yellow-page services: The Star*s Family as an example of diversified publishing, in Electronic Publishing for Physics and Astronomy, Heck A. (ed.). Kluwer Acad. Publ., Dordrecht, (see also the URL: http://vizier.u-strasbg.fr/starpages.html) p. 211-220

Heck A., 1998a, StarGuides 1998 - A directory of astronomy, space sciences and related organizations of the world, Publ. Spéc. CDS 30, viii + 1068 pp. (ISBN 2-908064-28-6)

Heck A., 1998b, Geographical distribution of observational activities in astronomy, A\&AS 130, 403

Heck A., Egret D., Ochsenbein F., 1994, A\&AS 108, 447-448 (see also the URLs: http://vizier.ustrasbg.fr/starworlds.html and http://vizier.u-strasbg.fr/ starbits.html) 